\title{
The Effect of Volcanic ash Pozzolan and Metakaolin on Electrochemical Corrosion Resistance of 2304 Duplex Stainless Steel Reinforcing in Concrete Subjected to Marine Environment
}

\author{
Wang Yujie*, Zhou Huiwen", Fu Xu \\ Department of Architectural Engineering, North China Institute of Aerospace Engineering, Hebei, \\ Langfang, 065000, China \\ *E-mail: wangyujie88123@163.com
}

Received: 1 December 2021 / Accepted: 14 January 2022 / Published: 2 February 2022

\begin{abstract}
The corrosion behavior of 2304 duplex stainless steel reinforcing in concrete structures containing natural basaltic volcanic ash pozzolan and metakaolin as partially replacing materials for Portland cement (PC) in 3.5wt\% NaCl solution as a marine environment was studied in this work. The corrosion resistance of stainless steel rebars was investigated using polarization assessment, electrochemical impedance spectroscopy (EIS), and a water absorption test. The concrete sample that included both basaltic volcanic ash pozzolan and metakaolin admixtures (BPMK) demonstrated superior steel reinforced concrete corrosion behavior. Water absorption is significantly reduced in the BPMK concrete sample. The passive current density in the BPMK sample was lower than in the other samples, showing that stainless steel reinforced concrete that included both basaltic volcanic ash and metakaolin admixtures has improved corrosion resistance. The EIS results show that the BPMK sample has a significant improvement in polarization resistance value, indicating greater corrosion resistance when compared to other samples.
\end{abstract}

Keywords: Electrochemical corrosion; Duplex stainless steel reinforcing in concrete; Electrochemical impedance spectroscopy; Polarization test

\section{$\underline{\text { FULL TEXT }}$}

(C) 2022 The Authors. Published by ESG (www.electrochemsci.org). This article is an open access article distributed under the terms and conditions of the Creative Commons Attribution license (http://creativecommons.org/licenses/by/4.0/). 